Article

\title{
Highly Selective Continuous Flow Hydrogenation of Cinnamaldehyde to Cinnamyl Alcohol in a $\mathrm{Pt} / \mathrm{SiO}_{2}$ Coated Tube Reactor
}

\author{
Yang Bai ${ }^{1}$, Nikolay Cherkasov ${ }^{1,2}{ }^{(1)}$, Steven Huband ${ }^{3}{ }^{(1)}$, David Walker ${ }^{3}$, Richard I. Walton ${ }^{4}$ and \\ Evgeny Rebrov 1,2,5,* (D) \\ 1 Stoli Catalysts Ltd., Coventry CV3 4DS, UK; y.bai@stolicatalysts.com (Y.B.); n.b.cherkasov@gmail.com (N.C.) \\ 2 School of Engineering, University of Warwick, Coventry CV4 7AL, UK \\ 3 Department of Physics, University of Warwick, Coventry CV4 7AL, UK; S.Huband@warwick.ac.uk (S.H.); \\ D.Walker.2@warwick.ac.uk (D.W.) \\ 4 Department of Chemistry, University of Warwick, Coventry CV4 7AL, UK; R.I.Walton@warwick.ac.uk \\ 5 Department of Biotechnology and Chemistry, Tver State Technical University, Nab. A. Nikitina 22, \\ Tver 170026, Russia \\ * Correspondence: e.rebrov@warwick.ac.uk; Tel.: +44-(0)24-765-22202
}

Received: 13 December 2017; Accepted: 29 January 2018; Published: 2 February 2018

\begin{abstract}
A novel continuous flow process for selective hydrogenation of $\alpha, \beta$-unsaturated aldehyde (cinnamaldehyde, CAL) to the unsaturated alcohol (cinnamyl alcohol, COL) has been reported in a tube reactor coated with a $\mathrm{Pt} / \mathrm{SiO}_{2}$ catalyst. A $90 \%$ selectivity towards the unsaturated alcohol was obtained at the aldehyde conversion of $98.8 \%$. This is a six-fold improvement in the selectivity compared to a batch process where acetals were the main reaction products. The increased selectivity in the tube reactor was caused by the suppression of acid sites responsible for the acetal formation after a short period on stream in the continuous process. In a fixed bed reactor, it had a similar acetal suppression phenomenon but showed lower product selectivity of about $47-72 \%$ due to mass transfer limitations. A minor change in selectivity and conversion caused by product inhibition was observed during the $110 \mathrm{~h}$ on stream with a turnover number (TON) reaching 3000 and an alcohol production throughput of $0.36 \mathrm{~kg} \mathrm{~g}_{\mathrm{Pt}}{ }^{-1}$ day $^{-1}$ in the single tube reactor. The catalysts performance after eight reaction cycles was fully restored by calcination in air at $400{ }^{\circ} \mathrm{C}$. The tube reactors provide an opportunity for process intensification by increasing the reaction rates by a factor of 2.5 at the reaction temperature of $150{ }^{\circ} \mathrm{C}$ compared to $90^{\circ} \mathrm{C}$ with no detrimental effects on catalyst stability or product selectivity.
\end{abstract}

Keywords: flow chemistry; hydrogenation; unsaturated aldehyde; platinum; tube reactor; alcohol; selectivity; stability; catalyst-coated

\section{Introduction}

Hydrogenation of cinnamaldehyde (CAL) is interesting not only due to wide applications of the valuable desired products [1-6], but also because it is a good model reaction to study structure-activity relationship of the catalysts $[7,8]$. The CAL molecule contains conjugated $\mathrm{C}=\mathrm{C}$ and $\mathrm{C}=\mathrm{O}$ bonds and an aromatic ring. The main catalytic routes of CAL hydrogenation in isopropanol (IPA) solvent are shown in Scheme 1. Hydrogenation of the $\mathrm{C}=\mathrm{O}$ group leads to cinnamyl alcohol (COL), while hydrogenation of the $\mathrm{C}=\mathrm{C}$ group forms hydrocinnamaldehyde (HCAL). Further hydrogenation of either COL or HCAL leads to the formation of hydrocinnamyl alcohol (HCOL). Other reactions such as aromatic ring hydrogenation or hydrogenolysis are possible, but these generally require considerably harsher conditions and are usually negligible $[9,10]$. The $C=C$ hydrogenation is thermodynamically 
favorable compared to the $\mathrm{C}=\mathrm{O}$ hydrogenation $[7,8,11]$. Thus, hydrogenation of $\mathrm{CAL}$ to $\mathrm{COL}$ has been viewed as one of the most challenging reactions in heterogeneous catalysis, primarily because of the difficulty in selectivity control $[7,8]$.

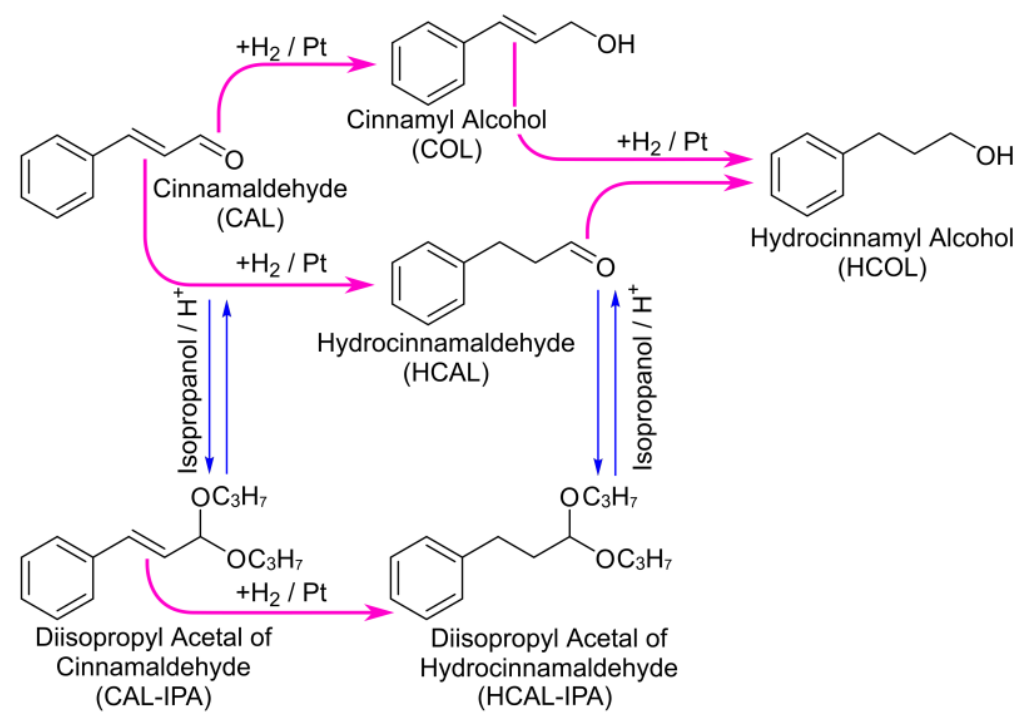

Scheme 1. The main reaction routes and side reactions during the catalytic hydrogenation of cinnamaldehyde.

Various factors such as the type of metal [12-15], particle size [16], additives [17-20] and supports $[1,4,16,21-23]$ were found to influence the activity and selectivity of the catalysts in CAL hydrogenation dramatically. In general, noble metals are used for the CAL hydrogenation because of their high activity at low temperatures. The selectivity towards COL generally decreases in the following order: $\mathrm{Os}>\mathrm{Ir}>\mathrm{Pt}>\mathrm{Ru}>\mathrm{Rh}>\mathrm{Pd}$ [7]. Due to the scarcity of Ir and toxicity of Os, $\mathrm{Pt}$ is the most promising catalyst for CAL hydrogenation.

The selectivity to COL improves as the particle size increases [7]. Because of the steric constraints caused by the aromatic ring, the planar CAL molecule cannot adsorb parallel to a flat metal surface (large particles) via the $\mathrm{C}=\mathrm{C}$ bond, so the head-on $(\mathrm{C}=\mathrm{O}) \mathrm{CAL}$ adsorption is preferred and leads to the hydrogenation to COL. Small particles which have high curvature do not show significant steric constraints, so CAL can be adsorbed via both $\mathrm{C}=\mathrm{C}$ and $\mathrm{C}=\mathrm{O}$ bonds. Thus, the relatively large nanoparticles ( $3-8 \mathrm{~nm}$ ) have a higher selectivity towards COL compared to the smaller nanoparticles [7]. The selectivity towards carbonyl reduction can be further increased by the addition of a second metal such as $\mathrm{Fe}, \mathrm{Co}, \mathrm{Sn}, \mathrm{Ge}[7,8,17,20]$. Additionally, the selectivity can be improved by optimising the porosity of the support. Mesoporous supports with controlled porosity demonstrate a larger surface area and stabilise the metal nanoparticles. Importantly, the pores of the catalyst support confine the CAL molecules decreasing the probability of the $\mathrm{C}=\mathrm{C}$ adsorption, and therefore increasing the COL selectivity [11]. However, introducing porosity and a second metal inevitably increases the complexity and costs of the entire process as well as compromises the catalyst reusability. For industrial applications, simpler and cheaper catalysts are more desirable.

Traditionally, catalytic hydrogenation reactions are conducted in continuously stirred tank reactors (CSTR), often needing elevated pressures and long reaction times [24-26]. These batch processes are highly versatile but the discontinuous nature of the batch process requires a lot of non-productive operations such as reactor cleaning and catalyst separation resulting in high labor costs [27]. Low heat and mass transfer rates decrease the process efficiency and the product yield as well [28-30]. The presence of toxic or hazardous compounds in large-volume, often pressurized vessels raises safety concerns and requires notable infrastructure costs. 
The problems of batch processes can be solved by a continuous flow operation which provides more efficient, safer and intensified processes [27-29]. Additionally, continuous flow processing benefits from the rapid removal of products and decreases the potential for catalyst poisoning which can reduce by-product formation [31]. The intrinsic problem of conventional micro-reactors with characteristic channel dimensions below $0.5 \mathrm{~mm}$ can be solved by increasing the channel diameter to the millimeter-range in milli-, or also called meso-, reactors. These systems offer all the benefits of conventional microreactors and enhanced scalability reaching up to a kilogram per day scale [32]. Therefore, the fine chemicals and pharmaceutical sectors have targeted a switchover from batch to continuous operation to improve process efficiency, atom economy and simplify scalability $[28,33]$. However, to the best of our knowledge, there are only a few reports that show limited success in cinnamaldehyde hydrogenation to cinnamyl alcohol in continuous flow with the highest selectivity towards unsaturated alcohol of about $60 \%$ [31,34,35].

In this paper, we aim to develop a new continuous process for selective hydrogenation of cinnamaldehyde to cinnamyl alcohol over a wall-coated catalyst tube reactor. We studied the effect of process conditions on the catalytic performance and stability of the reactors with a Pt/SiO 2 catalyst. The performance in a continuous tube reactor is compared to that in a batch reactor and a conventional fixed bed flow reactor.

\section{Results and Discussion}

\subsection{Catalyst Characterization}

Figure 1a presents characteristic scanning electron microscope (SEM) images of the catalytic coating in a tube reactor. The coating is uniform along the reactor length with a thickness of $28 \pm 3 \mu \mathrm{m}$. The morphology of the coating (Figure 1b) shows that $\mathrm{SiO}_{2}$ forms textured pillars with a diameter of $1.5 \mu \mathrm{m}$. The Pt loading of $12.5 \mathrm{wt} \%$ determined by energy-dispersive X-ray (EDX) spectroscopy analysis from several areas of the coating is in good agreement with the nominal loading of $12.0 \mathrm{wt} \%$. When focusing the electron beam on the catalyst coating, we found no traces of Fe in the EDX spectra which indicates complete coverage of the silica support over the stainless reactor body and no Pt-Fe interactions.
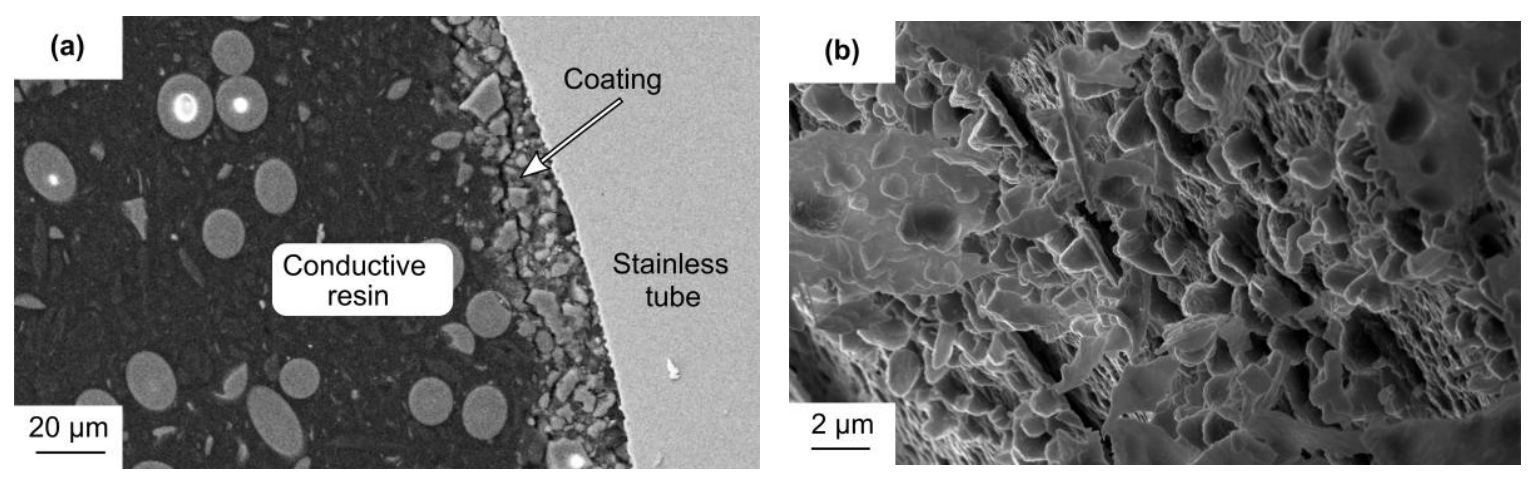

Figure 1. SEM (a) cross-sectional and (b) frontal images of the catalytic coating in a tube reactor.

Figure 2 shows a representative transmission electron microscopy (TEM) image of the $\mathrm{Pt} / \mathrm{SiO}_{2}$ coating. The average size of the Pt particle is $4.3 \pm 1.2 \mathrm{~nm}$ corresponding to a Pt dispersion of $28 \%$ [36]. The Brunauer-Emmett-Teller (BET) surface area and Barrett-Joyner-Halenda (BJH) pore-size distribution of $\mathrm{SiO}_{2}$ and $\mathrm{Pt} / \mathrm{SiO}_{2}$ are analyzed using $\mathrm{N}_{2}$ adsorption-desorption isotherms. Both samples show similar surface areas of $200 \mathrm{~m}^{2} \mathrm{~g}^{-1}$ and total pore volumes of $0.25 \mathrm{~mL} \mathrm{~g}^{-1}$. A narrow pore size distribution ranging from 3 to $5 \mathrm{~nm}$ with a maximum around $4 \mathrm{~nm}$ is evident for mesoporous $\mathrm{SiO}_{2}$ support (Figure 3). The pore size is reduced slightly after Pt loading with a distribution ranging from 3 to $4 \mathrm{~nm}$ and a maximum around $3.6 \mathrm{~nm}$. The presence of suitable mesopores is beneficial in stabilizing 
the Pt nanoparticles and improving the internal mass transfer in the coating which improves the COL selectivity $[11,37,38]$.

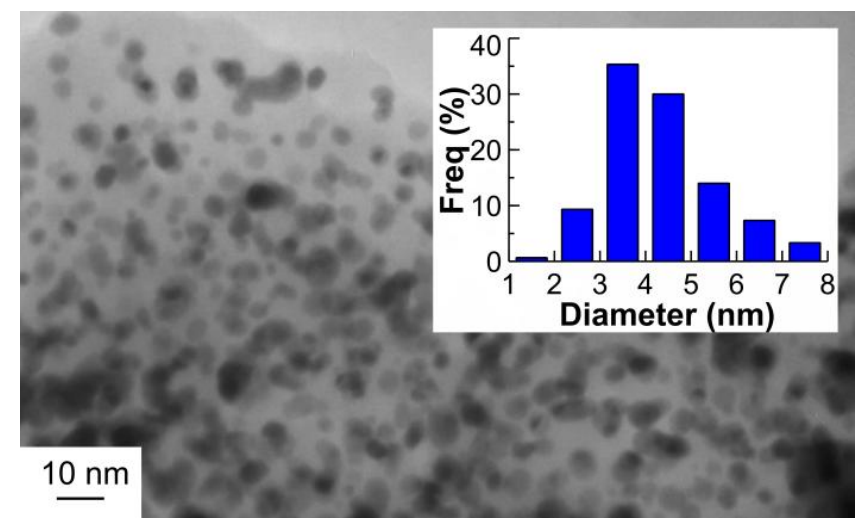

Figure 2. TEM image of the $\mathrm{Pt}$ nanoparticles supported on $\mathrm{SiO}_{2}$ with their diameter distribution.

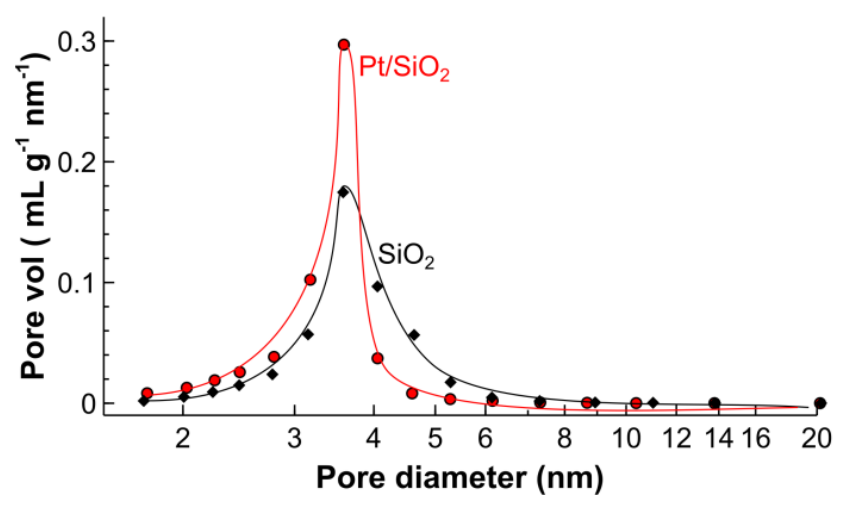

Figure 3. Barrett-Joyner-Halenda (BJH) desorption pore-size distribution for the $\mathrm{SiO}_{2}$ support and $\mathrm{Pt} / \mathrm{SiO}_{2}$ catalyst studied.

Powder X-ray diffraction patterns of the $\mathrm{Pt} / \mathrm{SiO}_{2}$ and $\mathrm{SiO}_{2}$ are shown in Figure 4. The (111) and (200) peaks are marked for the Pt nanoparticles. The average size of the Pt nanoparticles using the Scherrer method for the (111) peak was calculated to be $2.5 \pm 1 \mathrm{~nm}$ which is comparable with the result of TEM analysis. The pattern also shows the presence of $\mathrm{SiO}_{2}$ (100) which may also include an amorphous content.

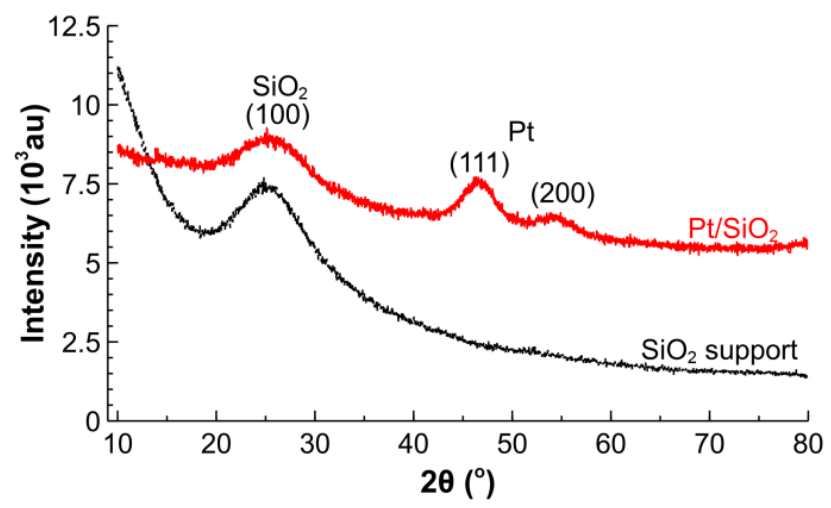

Figure 4. Powder X-ray diffraction patterns (using $\mathrm{Co} \mathrm{K}_{\alpha}$ radiation) for the $12 \mathrm{wt} \% \mathrm{Pt} / \mathrm{SiO}_{2}$ catalysts and the $\mathrm{SiO}_{2}$ support. 
Small angle X-ray scattering (SAXS) measurements are shown in Figure 5. The main features (marked by ${ }^{*}$ ) are from the structure formed by the silica spheres. The silica spheres commonly pack with face centered cubic (FCC) and hexagonally close packed (HCP) structures [39]. The peaks are too broad to determine which of these is dominant here. Assuming an FCC structure with the (001) peak at $q=0.044 \AA^{-1}$ gives an average sphere radius $\approx 8 \mathrm{~nm}$. Between $q=0.1$ and $0.3 \AA^{-1}$ there is an increase in intensity in the $\mathrm{Pt} / \mathrm{SiO}_{2}$ compared to the $\mathrm{SiO}_{2}$ sample due to the scattering from the $\mathrm{Pt}$ nanoparticles. A model treating the Pt nanoparticles as a Gaussian distribution of spheres was used alongside a simple power law slope to account for the $\mathrm{SiO}_{2}$ scattering in the same $q$ range. A unified fit method was used for fitting the power law slope developed by Beaucage and implemented within the Irena SAXS analysis package $[40,41]$. The power law slope was first fitted to the $\mathrm{SiO}_{2}$ only data in the $q$ range from 0.1 to $0.3 \AA^{-1}$ and then used for fitting the $\mathrm{Pt} / \mathrm{SiO}_{2}$ data in conjunction with a Gaussian distribution of $\mathrm{Pt}$ spheres. The overall fit for the $\mathrm{Pt} / \mathrm{SiO}_{2}$ is shown in Figure 5 as the blue line, along with the fit without scattering from the Pt particles shown by the dashed line. From this fit the mean $\mathrm{Pt}$ particle diameter is $2.5 \mathrm{~nm}$ with a standard deviation of $0.48 \mathrm{~nm}$, which is in good agreement with the TEM and XRD data.

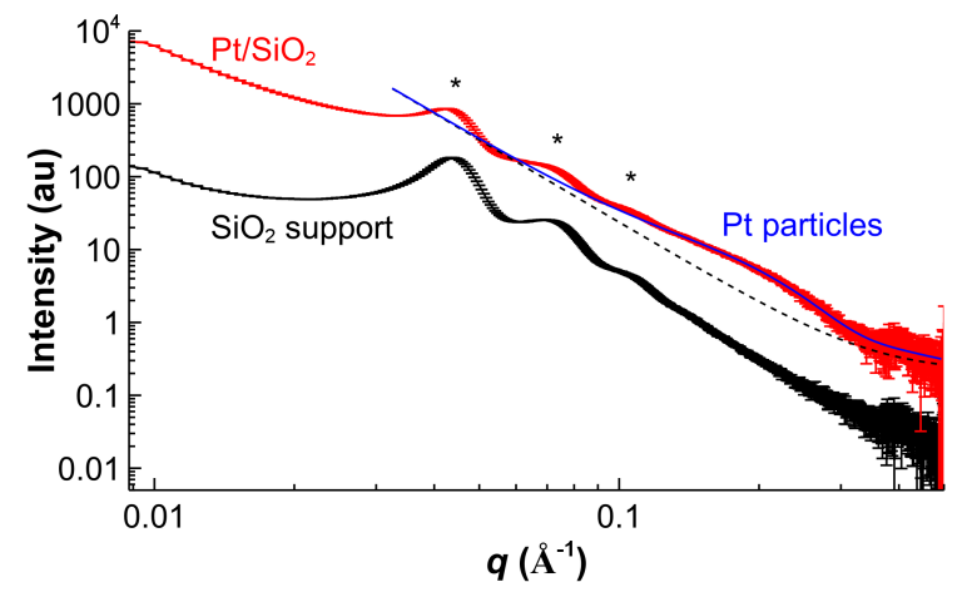

Figure 5. Small angle $X$-ray scattering obtained from the 12 wt $\% \mathrm{Pt} / \mathrm{SiO}_{2}$ catalysts and the $\mathrm{SiO}_{2}$ support. The overall fit for the $\mathrm{Pt} / \mathrm{SiO}_{2}$ is shown by the blue line and the fit without scattering from the $\mathrm{Pt}$ particles is given by the dashed line. The main features of $\mathrm{SiO}_{2}$ is marked by *

Acidity of the $\mathrm{Pt} / \mathrm{SiO}_{2}$ catalyst and $\mathrm{SiO}_{2}$ support was studied by pyridine temperatureprogrammed desorption (TPD). The materials held at $100{ }^{\circ} \mathrm{C}$ were dosed with the pyridine, flushed for $1.5 \mathrm{~h}$ with He followed by the temperature ramp (Figure 6). The silica support showed a small desorption peak with the maximum close to $170{ }^{\circ} \mathrm{C}$. The low desorption temperature indicates weak pyridine adsorption on the $\mathrm{SiO}_{2}$ support. The low adsorption observed agrees with the literature data which showed that amorphous silica does not contain acid sites and weak pyridine adsorption is associated with the hydrogen-bonded pyridine molecules over the silanol groups [42-44]. However, the $\mathrm{Pt} / \mathrm{SiO}_{2}$ catalyst showed much broader peaks centered at about $200{ }^{\circ} \mathrm{C}$ and $460{ }^{\circ} \mathrm{C}$. The total amount of the pyridine adsorbed on the $\mathrm{Pt} / \mathrm{SiO}_{2}$ catalyst compared to the $\mathrm{SiO}_{2}$ support increased substantially. The appearance of the peak centered at $460{ }^{\circ} \mathrm{C}$ indicates the formation of acid sites formed, likely at the vicinity of the Pt nanoparticles. The formation of new acidic groups on the $\mathrm{Pt} / \mathrm{SiO}_{2}$ catalysts agrees with the literature data, but strongly depends on the catalyst preparation method [45-47]. 


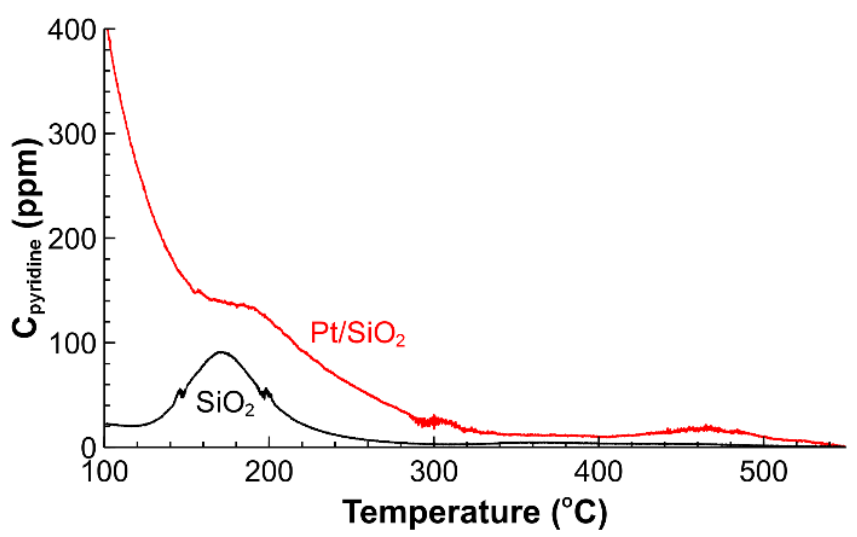

Figure 6. Temperature-programmed desorption profile of pyridine from the $\mathrm{Pt} / \mathrm{SiO}_{2}$ catalyst and $\mathrm{SiO}_{2}$ support.

\subsection{Hydrogenation of $\mathrm{CAL}$ over the $\mathrm{Pt} / \mathrm{SiO}_{2}$ Catalysts in Batch and Tube Reactors}

Firstly, the CAL hydrogenation was studied in a $\mathrm{Pt} / \mathrm{SiO}_{2}$ coated tube reactor by varying the residence time. Figure 7 shows that the CAL concentration decreased with the increasing residence time corresponding to a conversion change from $45.4 \%$ at $2.3 \mathrm{~min}$ to $99.2 \%$ at $10.5 \mathrm{~min}$. The main reaction product was COL with its concentration increasing gradually with residence time. Interestingly, the alcohol selectivity remained around $90 \%$ under all conditions studied. The data show a high selectivity of the $\mathrm{Pt} / \mathrm{SiO}_{2}$ catalytic coating to unsaturated alcohol. The average turnover frequency (TOF) was $130 \mathrm{~h}^{-1}$. The TOF numbers agree with the literature data for alkali-unpromoted hydrogenation of cinnamaldehyde over Pt catalysts [7,20,48,49]. The high selectivity observed might have been caused by the interaction with Fe from the reactor body as highlighted in recent publications $[20,48,50]$. However, the elemental EDX analysis showed no traces of Fe in the proximity of Pt likely due to the full coverage of the stainless tube with the silica support.

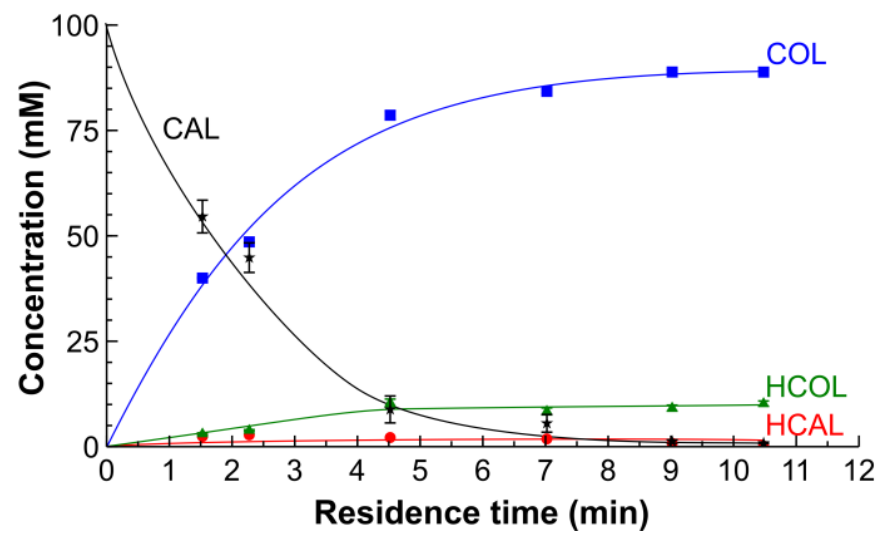

Figure 7. The outlet concentrations of the components obtained in the CAL hydrogenation as a function of residence time in the $5 \mathrm{~m}$ reactor coated with $190 \mathrm{mg} 12 \mathrm{wt} \% \mathrm{Pt} / \mathrm{SiO}_{2}$ catalyst. Reaction conditions: $\mathrm{H}_{2}$ flow rate: $4-12 \mathrm{~mL} \mathrm{~min}^{-1}$ (standard temperature and pressure, STP), liquid flow rate: $0.2-3 \mathrm{~mL}$ $\min ^{-1}$, inlet CAL concentration: $0.1 \mathrm{M}$ in IPA, pressure: $10 \mathrm{bar}$, temperature: $90^{\circ} \mathrm{C}$.

The same catalyst was also used for hydrogenation in a batch reactor as shown in Figure 8. Rather higher concentrations of by-products were observed in the batch reactor. Along with the hydrogenation products such as HCAL, HCOL (Scheme 1), substantial amounts of acetals (diisopropyl acetal of hydrocinnamaldehyde, HCAL-IPA and diisopropyl acetal of cinnamaldehyde, CAL-IPA) were obtained. The acetals are formed by a reversible acid-catalyzed reaction of CAL and HCAL with 
isopropanol $[9,10,16,21]$. It should be mentioned that the CAL-IPA concentration was considerably lower than HCAL-IPA although the CAL was present in a much higher concentration. The selectivity to the product of interest, COL, was only $15 \%$ which agrees with the literature for silica-supported $\mathrm{Pt}$ catalysts [51]. When acetals are formed, the $\mathrm{C}=\mathrm{O}$ group becomes protected and its hydrogenation is not possible which results in a decreased selectivity towards COL (Scheme 1). Therefore, a significant difference in the selectivity pattern between the catalyst-coated tube reactor and the batch reactor is likely associated with the acetal formation.

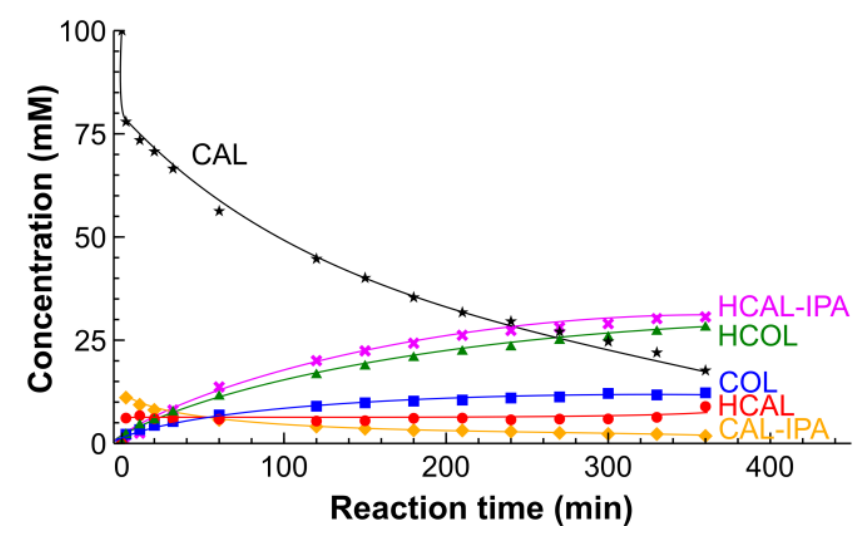

Figure 8. The outlet concentrations of the components obtained in the CAL hydrogenation as a function of residence time in a batch reactor. Reaction conditions: $0.1 \mathrm{~g} 12 \mathrm{wt} \% \mathrm{Pt} / \mathrm{SiO}_{2}, \mathrm{H}_{2}$ pressure $10 \mathrm{bar}$, $90^{\circ} \mathrm{C}, 0.1 \mathrm{M}$ CAL in IPA.

The higher amount of HCAL-IPA compared to CAL-IPA was studied in a series of blank experiments with and without the catalysts as shown in the Supplementary (Figure S1). The data indicate that the acetal formation rate is negligible in the absence of the catalyst. This is expected considering that acetal formation is an acid-catalyzed reaction. In the presence of the $\mathrm{Pt} / \mathrm{SiO}_{2}$ catalyst, the concentration of acetals increased rapidly obviously because of the presence of acid sites on the catalyst.

A high formation rate of acetals was observed over a fresh $\mathrm{Pt} / \mathrm{SiO}_{2}$ coating in the tube reactor. After $0.5-1.5 \mathrm{~h}$ on stream, the acetal formation was almost fully suppressed indicating deactivation of the acid sites which catalyze the acetal formation. Due to the acid site deactivation, the acetal formation becomes negligible and the CAL hydrogenation proceeds with a much higher COL selectivity over the $\mathrm{Pt} / \mathrm{SiO}_{2}$ coating.

An obvious solution to avoid the acetal formation may lie with utilization of other solvents such as hexane or toluene. Gallezot et al. [7] indicated that there is little solvent effect on the cinnamaldehyde hydrogenation. However, a number of reports show either a considerably lower hydrogenation activity or even complete catalyst deactivation in non-polar solvents compared to alcohols [10,52]. Our results also confirm negligible catalyst activity when the solvent was switched to toluene. Therefore, we used only isopropanol in the subsequent experiments.

The activity and selectivity observed over the $\mathrm{Pt} / \mathrm{SiO}_{2}$ catalyst in the coated tube reactor was considerably higher than that of monometallic $\mathrm{Pt}$ catalysts such as $\mathrm{Pt} / \mathrm{SiO}_{2}$ [31], $\mathrm{Pt} / \mathrm{Ti}$ [35] in the flow reactor and $\mathrm{Pt} / \mathrm{Graphite}$ and $\mathrm{Pt} / \mathrm{C}[12,23,53,54]$ in the batch reactors (Figure 9). The performance of $\mathrm{Pt} / \mathrm{SiO}_{2}$ coatings is comparable with that of bimetallic supported catalysts such as Pt-Co/SBA-15 [19]. A higher COL selectivity of above $90 \%$ was reported in CAL hydrogenation carried out in supercritical $\mathrm{CO}_{2}$, however the conversion was below 50\% [55,56]. While the selectivity above $90 \%$ was reported at full conversion over several catalysts such as $\mathrm{Pt}$ [24], Co [15] nanoparticles confined in metal-organic frameworks or bimetallic catalyst [20], their preparation is not straightforward and associated considerably higher catalyst costs. In addition, much longer residence time was needed (up to $48 \mathrm{~h}$ ) in those experiments. 


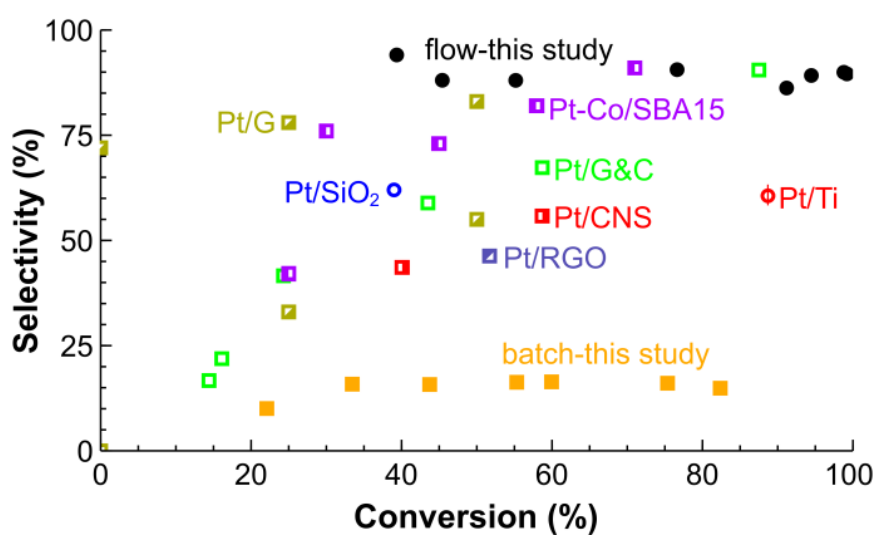

Figure 9. The selectivity to COL as a function of CAL conversion obtained in the current work over the $12 \mathrm{wt} \% \mathrm{Pt} / \mathrm{SiO}_{2}$ catalyst in the tube (flow-this study, $\bullet$ ) and batch (batch-this study, $\square$ ) reactors compared with the literature data in obtained in continuous flow reactors (Pt/Ti, $\Phi$ [35]; $\mathrm{Pt}_{/} / \mathrm{SiO}_{2}$ $\bigcirc$ [31]) and batch reactors (Pt/G\&C, $\square$ [12]; Pt-Co/SBA-15, \ [19]; Pt/CNS, घ [23]; Pt/RGO, $\square$ [53]; $\mathrm{Pt} / \mathrm{G}, \square[54])$. Circles represent continuous flow and squares represent batch reactors.

\subsection{Long-Term Stability}

High long-term catalyst stability is essential for the reactor operation under continuous flow. The reaction conditions were adjusted for the stability test to decrease liquid consumption and operate at $10-50 \%$ conversion range. The medium conversion range was selected to underline any deactivation phenomena. The results presented in Figure 10 show a minor loss of selectivity and increase in activity during the operation for over $110 \mathrm{~h}$ on stream. While the selectivity to COL decreased from $94 \%$ to $80 \%$ in $110 \mathrm{~h}$, both the selectivity to the by-products increased gradually (for HCAL-from $4 \%$ to $12 \%$ and for $\mathrm{HCOL}-$ from $1 \%$ to $7 \%$ ). The turnover number (TON), the ratio of the substrate molecules converted and the total amount of $\mathrm{Pt}$ in the catalyst, shows the practical longevity of the catalyst and reactor combination used. TON exceeded 3000 in $110 \mathrm{~h}$ compared to typical TON of 65 [48], 760 [6], 840 [49] in batch reactors as estimated from available literature data. Therefore, the TON value obtained over the $\mathrm{Pt} / \mathrm{SiO}_{2}$ catalytic coating is 1-2 orders of magnitude higher than the value observed in batch reactors. Even comparing with a more efficient magnetic catalyst separation technique in batch $[57,58]$, the tube reactors provide higher catalyst utilization efficiency due to the continuous $24 / 7$ operation with neither laborious catalyst separation steps nor idle time.

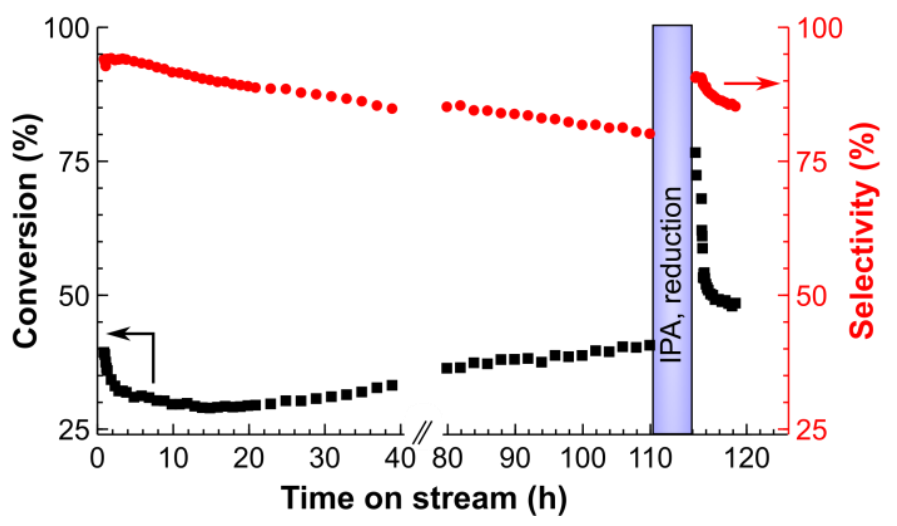

Figure 10. The stability test of the $5 \mathrm{~m}$ tube reactor coated with a $12 \mathrm{wt} \% \mathrm{Pt} / \mathrm{SiO}_{2}$ catalyst. Reaction

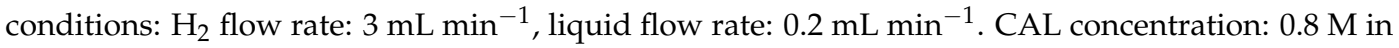
IPA, pressure: 15 bar and temperature: $90^{\circ} \mathrm{C}$. Reduction was performed in the flow of isopropanol $\left(1 \mathrm{~mL} \mathrm{~min}^{-1}\right)$ and $\mathrm{H}_{2}$ flow rate $\left(3 \mathrm{~mL} \mathrm{~min}{ }^{-1}, \mathrm{STP}\right)$ for $10 \mathrm{~min}$. The duration of the reduction step on the plot is exaggerated for the presentation purposes. 
Flushing with $\mathrm{H}_{2}$ and IPA for $10 \mathrm{~min}$ under the same conditions after $110 \mathrm{~h}$ on stream recovered most of the activity and significantly increased the selectivity. However, a rapid deactivation was observed after the reduction step as the conversion reduced from 76 to $53 \%$ over the first $30 \mathrm{~min}$ after the reduction. This behavior agrees with previous reports describing a significant effect of hydrogen pre-activation step on the reaction kinetics. This also suggests a significant product inhibition of the catalysts [35].

The changes in the CAL conversion over time were also remarkable. The conversion decreased during the first $20 \mathrm{~h}$ on stream and then gradually increased up to $110 \mathrm{~h}$ and become even higher after the reduction treatment. The leaching study of the reaction products showed the $\mathrm{Pt}$ concentration in the final products was only $0.002 \mathrm{ppm}$. Low leaching observed demonstrates that $\mathrm{Pt}$ nanoparticles are confined in the mesoporous structure of the catalyst support $\left(\mathrm{SiO}_{2}\right)$ and confirms the high long-term stability of the coatings.

An additional study was performed at a higher temperature to explore a possibility for intensified process conditions. The details are reported in Supplementary (Figure S2). The activation energy for the CAL hydrogenation considering zero-order kinetics was determined to be $31.2 \mathrm{~kJ} \mathrm{~mol}^{-1}$, which is in reasonable agreement with the literature data for a $\mathrm{Pd} / \mathrm{SiO}_{2}$ catalyst $\left(30.1 \mathrm{~kJ} \mathrm{~mol}^{-1}\right)$ [59]. The conversion increased by a factor of 2.5 when changing the temperature from $90{ }^{\circ} \mathrm{C}$ to $150{ }^{\circ} \mathrm{C}$ allowing for process intensification.

Due to higher reaction rates at elevated temperatures, a shorter reactor $(2 \mathrm{~m})$ was used to study the long-term stability and explore possible regeneration of the $\mathrm{Pt} / \mathrm{SiO}_{2}$ catalytic coatings. In these experiments, the catalysts reduction and solvent treatment steps were repeated every $10 \mathrm{~h}$ to study their effect on catalyst performance. Finally, an oxidation treatment at $400{ }^{\circ} \mathrm{C}$ was performed after eight reaction-reduction cycles.

The activity and selectivity pattern of CAL hydrogenation performed at $150{ }^{\circ} \mathrm{C}$ follows the same trend as that at $90^{\circ} \mathrm{C}$ (Figure 11). A combined reduction and solvent washing treatment can restore the selectivity significantly after every single cycle, however, the selectivity was slowly decreasing over time from 90 to $80 \%$. Similarly, the conversion decreases with time in every cycle, however the reduction treatment restores or even increases the overall reaction rate. The notable effect of reduction and solvent washing demonstrates a strong product inhibition. The calcination treatment at $400{ }^{\circ} \mathrm{C}$ restores the selectivity which reaches the value observed over the fresh sample (90\%) demonstrating excellent sintering stability and reusability of the catalytic coatings.

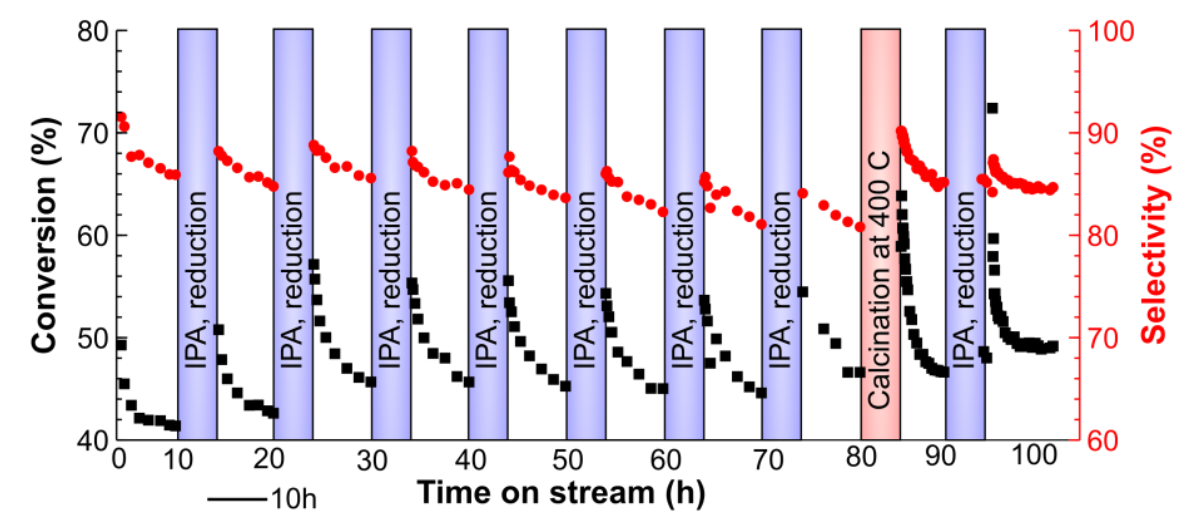

Figure 11. The stability test of the $2 \mathrm{~m}$ tube reactor coated with a $12 \mathrm{wt} \% \mathrm{Pt} / \mathrm{SiO}_{2}$ catalyst. Reaction

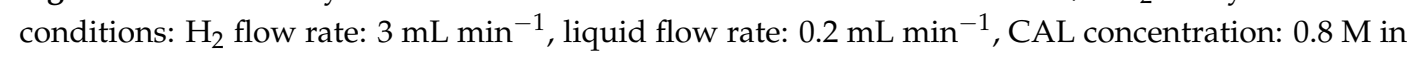
IPA, pressure: 15 bar and temperature: $150^{\circ} \mathrm{C}$. Reduction was performed in the flow of isopropanol $\left(1 \mathrm{~mL} \mathrm{~min}^{-1}\right)$ and $\mathrm{H}_{2}$ flow rate $\left(3 \mathrm{~mL} \mathrm{~min}^{-1}, \mathrm{STP}\right)$ for $10 \mathrm{~min}$. Regeneration conditions: in air at $400{ }^{\circ} \mathrm{C}$ for $1 \mathrm{~h}$. The duration of the reduction and calcination steps on the plot are exaggerated for the presentation purposes. 
The stability test of a continuous fixed bed reactor packed with $190 \mathrm{mg} 12 \mathrm{wt} \% \mathrm{Pt} / \mathrm{SiO}_{2}$ catalyst was carried out under the same conditions (Figure 12). The results in Figure 12a explained why the selectivity of COL was much higher than that in the batch reactor. A fresh $\mathrm{Pt} / \mathrm{SiO}_{2}$ catalyst also produced high concentration of acetals at the beginning, but after $0.5-2.5 \mathrm{~h}$ on stream, the acetal formation was almost fully suppressed which results in a much higher COL selectivity in the flow reactors. The selectivity of COL increased from 47 to $72 \%$ in the first few hours and slowly dropped to $47 \%$ in $66 \mathrm{~h}$, shown in Figure 12b. The range of the selectivity to COL is comparable to the other results produced in fixed bed [31]. The conversion decreased from 57 to $15 \%$ in $8 \mathrm{~h}$ and stabilized afterwards. Much lower conversion and selectivity were found compared with the performance of the catalyst-coated tube reactor. The likely reasons are the mass transfer limitations, broad residence time distribution associated with the possibility of liquid channeling [60-62].
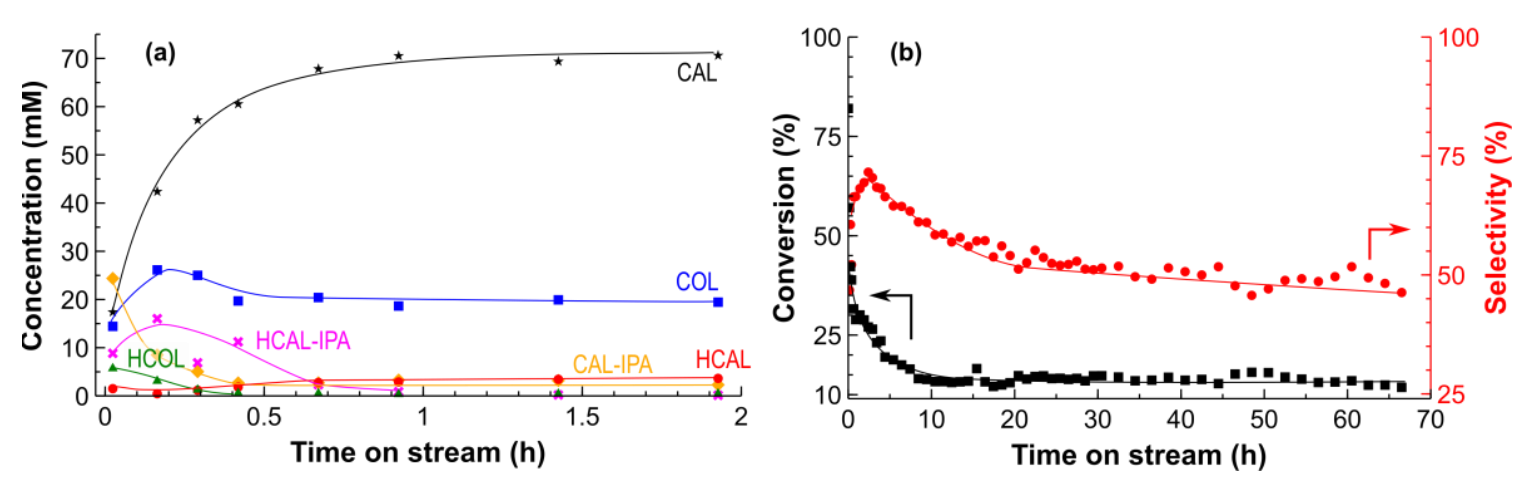

Figure 12. The stability test of a continuous fixed bed reactor packed with $190 \mathrm{mg} 12 \mathrm{wt} \% \mathrm{Pt} / \mathrm{SiO}_{2}$. Reaction conditions: $\mathrm{H}_{2}$ flow rate: $3 \mathrm{~mL} \mathrm{~min}^{-1}$, liquid flow rate: $0.2 \mathrm{~mL} \mathrm{~min}{ }^{-1}$, CAL concentration: $0.8 \mathrm{M}$ in IPA, pressure: 15 bar and temperature: $90^{\circ} \mathrm{C}$. (a) The outlet concentrations of the components obtained in the CAL hydrogenation as a function of time in stream. (b) The conversion of CAL and the selectivity to COL vs. Time on stream.

A combination of excellent catalytic activity, stability and selectivity in a tube reactor is promising for innovator pharma applications which are at gram to kilogram scale. The total production in $6 \mathrm{~h}$ over the $\mathrm{Pt} / \mathrm{SiO}_{2}$ coatings in the tube reactor was 7.5 times and 1.5 times higher compared to a batch reactor and a fixed bed reactor, respectively (Figure 13). The advantage becomes more significant over time because of required catalyst changeovers will further decrease the space-time yield in the batch reactor. A product throughput of $0.36 \mathrm{~kg} \mathrm{~g}_{\mathrm{pt}}{ }^{-1}$ day $^{-1}$ was achieved in a single continuous flow catalyst-coated tube reactor. The best literature data reports a throughput of $0.13 \mathrm{~kg} \mathrm{gpt}^{-1}$ day $^{-1}$ being obtained under much higher temperature and pressure [31,35]. There exists a possibility for further scale up to a $10 \mathrm{~kg} \mathrm{~g}^{-1}$ day $^{-1}$ by operating 32 tubes in parallel following the numbering up approach in a gas-liquid modular manifold [63,64]. A very low-pressure drop in the catalyst-coated tube reactor also allows increasing the reactor length by connecting the reactors in series. The main advantages of using the catalyst-coated tube reactors in the continuous flow process are higher throughout of product, the absence of catalyst separation from the products, negligible pressure drop, easy scalability, efficient energy utilization and safe operation. 


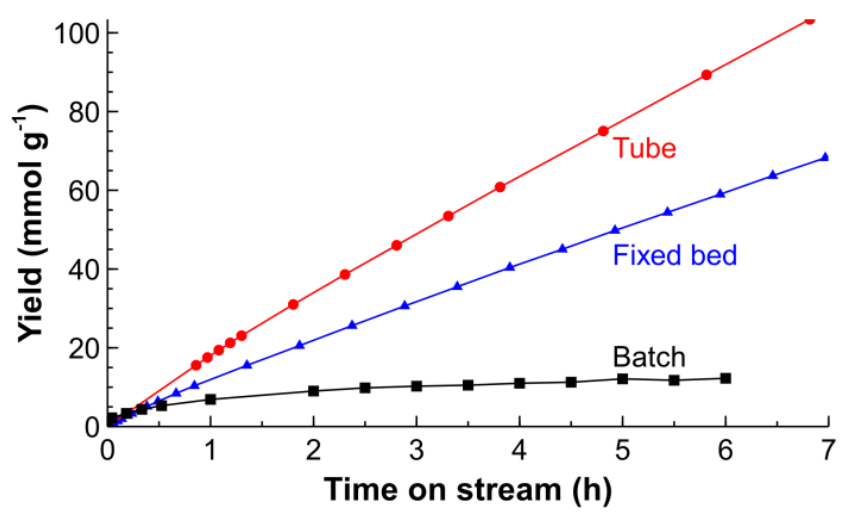

Figure 13. The comparison of cumulative $\mathrm{COL}$ yield over the $\mathrm{Pt} / \mathrm{SiO}_{2}$ catalysts in batch, fixed bed and tube reactors at the same condition $\left(0.1 \mathrm{~g} 12 \mathrm{wt} \% \mathrm{Pt} / \mathrm{SiO}_{2}, \mathrm{CAL}\right.$ concentration: $0.1 \mathrm{M}$ in IPA, pressure: 10 bar and temperature: $90^{\circ} \mathrm{C}$ ).

\section{Materials and Methods}

\subsection{Materials}

Trans-cinnamaldehyde (CAL, 98 wt \%) was purchased from Alfa Aesar (Heysham, UK) and stored under $\mathrm{N}_{2}$. Isopropanol (IPA, $99.5 \mathrm{wt} \%$ ) used as a solvent was obtained from Fisher Scientific (Loughborough, UK) and tetradecane ( $99 \mathrm{wt} \%$ ) as internal standard for GC analysis was ordered from Acros Organics (Linden, NJ, USA). The wall-coated $\mathrm{Pt} / \mathrm{SiO}_{2}$ tube reactors and identical powder $\mathrm{Pt} / \mathrm{SiO}_{2}$ catalyst were provided by Stoli Catalysts Ltd. (Stoli Catalysts Ltd., Coventry, UK). The detailed synthesis methodology is being patented (not yet public) $[65,66]$ and cannot be disclosed. The coating was obtained by sol-gel method similar to the previously reported papers [67-69].

\subsection{Materials Characterization}

A typical tube reactor was a $5 \mathrm{~m}$ long with the $316 \mathrm{~L}$ stainless steel tubing (OD: $1.60 \mathrm{~mm}$, ID: $1.27 \mathrm{~mm}$ ) body coated with $190 \mathrm{mg}$ of a $12 \mathrm{wt} \% \mathrm{Pt} / \mathrm{SiO}_{2}$ catalyst (Figure 14). Several cross-sections of catalyst-coated tube reactor were studied using a Carl Zeiss Sigma scanning electron microscope equipped with an energy-dispersive X-ray detector (Oxford Instruments, Abingdon, UK). The catalyst tube was filled with a conductive resin to ensure that the coating layer is not damaged during the polishing. The Pt loading was determined by EDX taken at several areas along the coating.

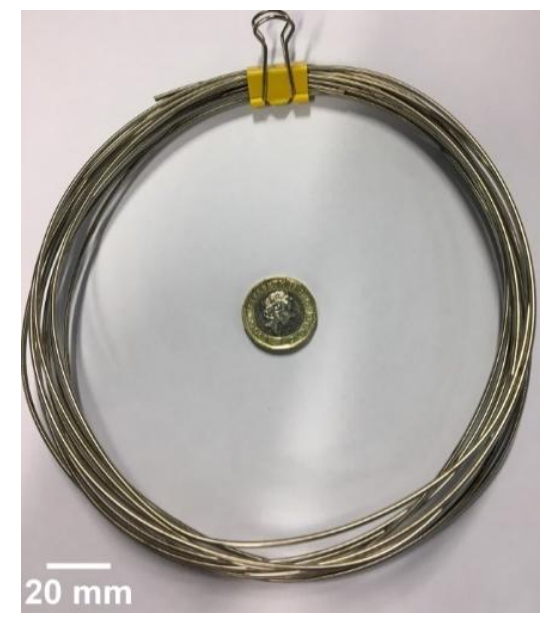

Figure 14. Photograph of a $5 \mathrm{~m} 1.27 \mathrm{~mm} \mathrm{ID} \mathrm{Pt/SiO}$ coated tube reactor along with a pound coin for scale. 
The specific surface area and pore volume were determined from nitrogen adsorption-desorption isotherms using a Micromeritics ASAP 2020 instruments (Norcross, GA, USA). For these experiments, the catalytic coating was mechanically removed from the tube, dried at $160{ }^{\circ} \mathrm{C}$ under vacuum for $5 \mathrm{~h}$ prior to the measurements. The powder obtained was also redispersed in acetone and applied on a carbon-coated copper grid. Several images with more than $100 \mathrm{Pt}$ nanoparticles were obtained using a Jeol 2000FX transmission electron microscope (Akishima, Tokyo, Japan). From these images, the particle size distribution was obtained by ImageJ software (V 1.4.3.67) [70].

Powder X-ray diffraction (XRD) patterns were measured between $10-80^{\circ}(2 \theta)$ on a PANalytical Empyrean diffractometer in Bragg-Brentano geometry with Co $K_{\alpha}$ radiation (1.7903 ̊) (Malvern Panalytical B.V., Almelo, The Netherlands). A beam knife was used to reduce the air scatter at low angles. Small-angle X-ray scattering (SAXS) measurements were made using a Xenocs Xeuss 2.0 equipped (Sassenage, France) with a micro-focus $\mathrm{Cu} \mathrm{K} \mathrm{K}_{\alpha}$ source collimated with Scatterless slits. The scattering was measured using a Pilatus $300 \mathrm{~K}$ detector with a pixel size of $0.172 \mu \mathrm{m} \times 0.172 \mu \mathrm{m}$. The detector was translated vertically and the images combined to form a virtual detector with double the number of pixels. The distance between the detector and the sample was calibrated using silver behenate $\left(\mathrm{AgC}_{22} \mathrm{H}_{43} \mathrm{O}_{2}\right)$, giving a value of $1.192(5) \mathrm{m}$. The magnitude of the scattering vector $(q)$ is given by $q=4 \pi \sin \theta / \lambda$, where $2 \theta$ is the angle between the incident and scattered X-ray and $\lambda$ is the wavelength of the incident X-rays. This results in a $q$ range for the detector of $0.01 \AA^{-1}$ to $0.5 \AA^{-1}$. The powder samples were mounted between two sticky Kapton windows. A radial integration as function of $q$ was performed on the 2D scattering profile and the resulting data corrected for the sample absorption and background from the sample holder.

The temperature-programmed desorption (TPD) experiment was performed by placing the $50 \mathrm{mg}$ powdered sample into a quartz tube $4 \mathrm{~mm}$ ID between 2 layers of quartz wool. The quartz tube was placed into a tube furnace and connected to a system presented in Figure 15. Prior to the measurements, the sample was calcined at $550{ }^{\circ} \mathrm{C}$ in the flow of $10 \mathrm{vol} \% \mathrm{O}_{2}$ in He in the total flow rate of $12 \mathrm{~mL} \mathrm{~min}{ }^{-1}$ (standard temperature and pressure, STP) and cooled down to $100{ }^{\circ} \mathrm{C}$ in the flow of He. Afterwards, pyridine was introduced by passing a flow of $\mathrm{He} 4 \mathrm{~mL} \mathrm{~min}^{-1}$ (STP) through a vessel with liquid pyridine at the temperature of $14.7^{\circ} \mathrm{C}$ for $30 \mathrm{~min}$. The sample held at $100{ }^{\circ} \mathrm{C}$ was then purged with a He flow of $13 \mathrm{~mL} \mathrm{~min}{ }^{-1}$ (STP) for $2 \mathrm{~h}$ to remove the weakly adsorbed species followed by the temperature ramping to $550{ }^{\circ} \mathrm{C}$ at the heating rate of $8{ }^{\circ} \mathrm{C} \mathrm{min}^{-1}$. The gases from the quartz reactor passed through the PTFE tubing to minimize adsorption [71] into a quadrupole mass spectrometer that monitored the concentration of pyridine.

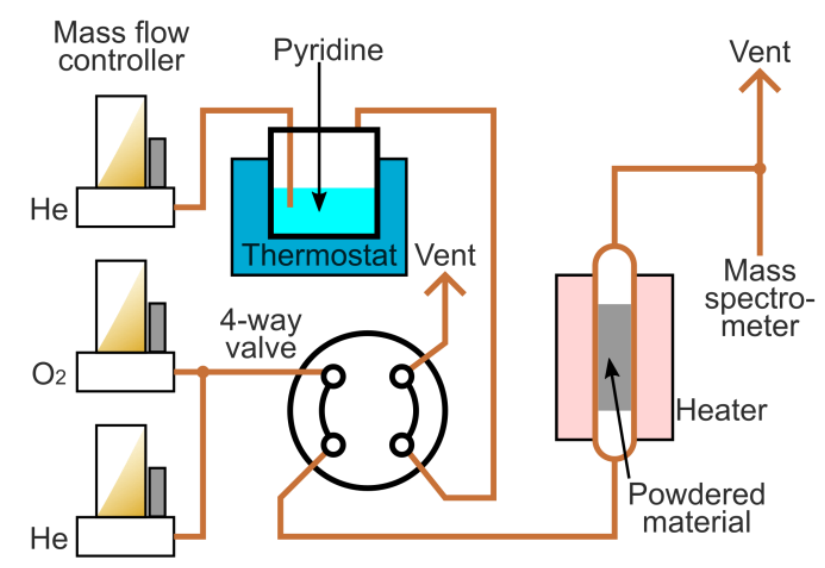

Figure 15. The scheme of the setup used for the pyridine chemisorption study.

\subsection{Hydrogenation in a Continuous Flow System}

The continuous flow system used for the testing is schematically presented in Figure 16. The photograph of the system was shown in our recent paper [72]. The CAL solution (IPA as solvent) 
was fed with a HPLC pump (Knauer P4.1S HPLC pump, Berlin, Germany). The $\mathrm{H}_{2}$ gas was fed with a mass flow controller (Bronkhorst, Suffolk, UK). The reactor (tube or fixed bed) was placed in a convection oven (Carbolite Gero, Parsons Lane, Hope, UK). The pressure in the reactor was maintained by a back-pressure regulator (Equilibar, Fletcher, NC, USA). The system was operated in a fully automated mode with the samples taken for analysis into vials equipped with septa to minimize sample evaporation. The collection time was at least 3 times the liquid residence time to ensure a representative sample. The sampling was repeated at least twice for every measurement to ensure reproducibility. The analysis of liquid samples was performed by an offline gas chromatograph Shimadzu GC-2010 plus equipped with an Agilent DB-5 $30 \mathrm{~m} 0.25 \mathrm{~mm}$ ID column and an FID detector (Kyoto, Kyoto Prefecture, Japan).

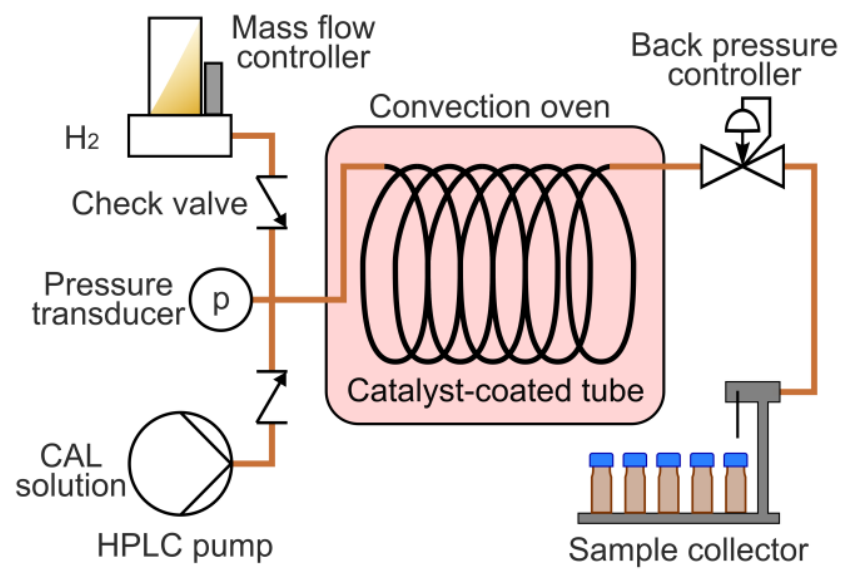

Figure 16. The scheme of the continuous flow hydrogenation system.

A reference fixed-bed study was performed in a glass column of $6.6 \mathrm{~mm}$ internal diameter (Omnifit, Kinesis Inc., Vernon Hills, IL, USA) filled with $190 \mathrm{mg}$ of the same $\mathrm{Pt} / \mathrm{SiO}_{2}$ powder packed between 2 layers of glass beads ( $100 \mu \mathrm{m}$ in diameter). The fixed bed was placed into the same system used for the tube reactors and operated by the same procedure.

Prior to the experiments, the catalyst was reduced in-situ in the $\mathrm{H}_{2}$ flow of $10 \mathrm{~mL} \mathrm{~min}^{-1}$ (STP) for $30 \mathrm{~min}$ at $50^{\circ} \mathrm{C}$. Leaching of Pt during the reaction was analyzed by concentrating about $1 \mathrm{~L}$ of the product solution to about $5 \mathrm{~mL}$ by evaporating the substances, extracting $\mathrm{Pt}$ with aqua regia on heating and analyzing the aqueous extract using the inductively coupled plasma-optical emission spectrometry (ICP-OES) using a PerkinElmer 5300 DV ICP-OES instrument (Waltham, MA, USA).

The CAL conversion was calculated by Equation (1), and the COL selectivity was calculated by Equation (2).

$$
\begin{gathered}
X_{C A L}=1-\frac{C_{C A L}}{C_{C O L}+C_{H C A L}+C_{H C O L}+C_{\text {others }}} \\
S_{C O L}=\frac{C_{C O L}}{C_{C O L}+C_{H C A L}+C_{H C O L}+C_{\text {others }}}
\end{gathered}
$$

where $C_{i}$ represents concentrations of reactants and products which determined by the GC analysis.

Taylor flow with the alternating gas and liquid slugs was observed under all the conditions studied [73]. The average liquid residence time in the flow reactor was estimated by Equation (3).

$$
\tau_{\text {res }}=\frac{V_{r}}{F_{L}+\frac{F_{g}}{p}}
$$

where $V_{r}$ is the reactor volume, $F_{L}$ is the liquid flow rate, $F_{g}$ is the gas flow rate (STP) and $p$ is the reactor pressure. 
The turn-over number (TON) was calculated by Equation (4).

$$
T O N=\frac{C_{C A L, i n} \overline{X_{C A L}} F_{L} t}{n_{P t}}
$$

where $C_{C A L, \text { in }}$ is the inlet reactant concentration of $C A L, \overline{X_{C A L}}$ is the average conversion during the time on stream $(t), n_{P t}$ is the total moles of Pt on the coating.

The turn over frequency (TOF) was obtained by Equation (5):

$$
T O F=\frac{C_{C A L, i n} \overline{X_{C A L}} Q}{n_{P t} D}
$$

where $D$ is the Pt dispersion, which was obtained by Equation (6) [36].

$$
D=\left(3.32 \frac{d_{P t}}{d_{p}}\right)^{0.813}
$$

where $d_{P t}$ is the Pt atomic diameter and $d_{p}$ is the nanoparticle diameter obtained from the TEM images.

\subsection{Hydrogenation in a Batch Reactor}

The batch hydrogenation was performed in a $160 \mathrm{~mL}$ stainless steel autoclave reactor (Parr) at a stirring rate of $1200 \mathrm{rpm}$ under the same temperature, pressure and the substrate concentration as in the flow experiments. A total liquid volume of $100 \mathrm{~mL}$ was used. The $\mathrm{Pt} / \mathrm{SiO}_{2}$ catalyst $(0.1 \mathrm{~g})$ was dispersed in isopropanol (IPA, $90 \mathrm{~mL}$ ) and reduced in situ for $15 \mathrm{~min}$ in $\mathrm{H}_{2}$ at $90{ }^{\circ} \mathrm{C}$. Then a $1.0 \mathrm{M}$ CAL solution $(10 \mathrm{~mL})$ containing $0.1 \mathrm{M}$ tetradecane (internal standard) was added. The reactor was pressurized to start the reaction. The liquid mixture was sampled periodically and analyzed by the same offline GC.

\section{Conclusions}

A selectivity of $90.0 \%$ to cinnamyl alcohol at a $98.8 \%$ conversion of cinnamaldehyde was achieved in a continuous flow tube reactor wall-coated with a $12 \mathrm{wt} \% \mathrm{Pt} / \mathrm{SiO}_{2}$ catalyst at $90{ }^{\circ} \mathrm{C}$ and a pressure of 10 bar. After a short period on stream, the formation of acetals was completely suppressed in the catalyst-coated tube reactor substantially increasing the selectivity to the target product. Both activity and selectivity were higher than that in the batch and fixed bed reactor at the same conditions. A turnover number of 3000 was reached in the flow reactor in $110 \mathrm{~h}$ and it enables to reduce catalyst costs by an order of magnitude. The change in the reaction rates over time demonstrated a strong product inhibition. The activity and selectivity were restored after a combined reduction and solvent flushing treatment performed in $10 \mathrm{~h}$ intervals. A calcination treatment of catalyst regeneration after eight reaction cycles completely restored the initial activity and selectivity. A product throughput of

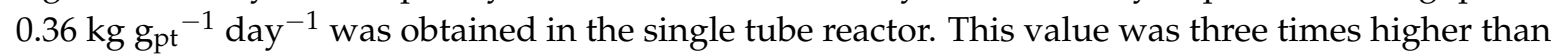
previously reported in literature. A possibility for further process intensification was demonstrated by the operation at higher temperature and even shorter residence times. The reaction rate was increased by 2.5 times at $150{ }^{\circ} \mathrm{C}$ without major decay in selectivity. Also the deactivation rates and catalyst leaching levels remained similar to that observed at $90^{\circ} \mathrm{C}$. Furthermore, the catalyst does not need to be separated from the substrates or the products by filtration or centrifugation after the completion of reactions, because it was coated inside of the reactor.

Supplementary Materials: The following are available online at http:/ / www.mdpi.com/2073-4344/8/2/58/s1, Figure S1. Acetal formation with CAL and HCAL. Figure S2. Increasing reaction rate with the reaction temperature.

Acknowledgments: The authors are grateful to Jonathan Strong for the ICP and TEM analysis, Guannan Hu for the SEM study of the $\mathrm{Pt} / \mathrm{SiO}_{2}$ catalyst. We also acknowledge the support of the European Research Council Proof of Concept grant (project Micarf 693739) and InnovateUK grant (900041) for funding this research. 
Author Contributions: Y.B., N.C. and E.R. conceived and designed the experiments; Y.B. performed the experiments; S.H., D.W. and R.I.W. did the XRD and SAXS characterizations. Y.B. and N.C. did the other material characterizations; all authors analyzed the data. All authors contributed to writing the paper.

Conflicts of Interest: The authors declare no conflict of interest.

\section{References}

1. Zhang, Y.; Zhang, S.; Pan, X.; Bao, M.; Huang, J.; Shen, W. Selective Hydrogenation of Cinnamaldehyde to Cinnamyl Alcohol over Au Catalysts: Influence of the Oxide-Supports. Catal. Lett. 2017, 147, 102-109. [CrossRef]

2. Yang, X.; Chen, D.; Liao, S.; Song, H.; Li, Y.; Fu, Z.; Su, Y. High-performance Pd-Au bimetallic catalyst with mesoporous silica nanoparticles as support and its catalysis of cinnamaldehyde hydrogenation. J. Catal. 2012, 291, 36-43. [CrossRef]

3. Chen, S.; Meng, L.; Chen, B.; Chen, W.; Duan, X.; Huang, X.; Zhang, B.; Fu, H.; Wan, Y. Poison Tolerance to the Selective Hydrogenation of Cinnamaldehyde in Water over an Ordered Mesoporous Carbonaceous Composite Supported Pd Catalyst. ACS Catal. 2017. [CrossRef]

4. Song, S.; Liu, X.; Li, J.; Pan, J.; Wang, F.; Xing, Y.; Wang, X.; Liu, X.; Zhang, H. Confining the Nucleation of Pt to In Situ Form (Pt-Enriched Cage)@CeO 2 Core@Shell Nanostructure as Excellent Catalysts for Hydrogenation Reactions. Adv. Mater. 2017, 29, 1700495. [CrossRef] [PubMed]

5. Plessers, E.; De Vos, D.E.; Roeffaers, M.B.J. Chemoselective reduction of $\alpha$, $\beta$-unsaturated carbonyl compounds with UiO-66 materials. J. Catal. 2016, 340, 136-143. [CrossRef]

6. Tian, Z.; Li, Q.; Hou, J.; Li, Y.; Ai, S. Highly selective hydrogenation of $\alpha, \beta$-unsaturated aldehydes by Pt catalysts supported on Fe-based layered double hydroxides and derived mixed metal oxides. Catal. Sci. Technol. 2016, 6, 703-707. [CrossRef]

7. Gallezot, P.; Richard, D. Selective Hydrogenation of $\alpha$, $\beta$-Unsaturated Aldehydes. Catal. Rev. 1998, 40, 81-126. [CrossRef]

8. Mäki-Arvela, P.; Hájek, J.; Salmi, T.; Murzin, D.Y. Chemoselective hydrogenation of carbonyl compounds over heterogeneous catalysts. Appl. Catal. A Gen. 2005, 292, 1-49. [CrossRef]

9. Kumar, N.; Salmi, T.; Murzin, D.Y. Impact of Catalyst Reduction Mode on Selective Hydrogenation of Cinnamaldehyde over Ru-Sn Sol-Gel Catalysts. Ind. Eng. Chem. Res. 2003, 42, 295-305.

10. Hájek, J.; Kumar, N.; Mäki-arvela, P.; Salmi, T.; Murzin, D.Y.; Paseka, I.; Heikkilä, T.; Laine, E.; Laukkanen, P.; Väyrynen, J. Ruthenium-modified MCM-41 mesoporous molecular sieve and Y zeolite catalysts for selective hydrogenation of cinnamaldehyde. Appl. Catal. A Gen. 2003, 251, 385-396. [CrossRef]

11. Rebrov, E.V. Heterogeneous Catalysis in Microreactors. In Microreactors in Preparative Chemistry: Practical Aspects in Bioprocessing, Nanotechnology, Catalysis and More; John Wiley \& Sons: Hoboken, NJ, USA, 2013; pp. 243-271. ISBN 9783527652891.

12. Giroir-Fendler, A.; Richard, D.; Gallezot, P. Selectivity in cinnamaldehyde hydrogenation of group-VIII metals supported on graphite and carbon. Stud. Surf. Sci. Catal. 1988, 41, 171-178. [CrossRef]

13. Claus, P. Selective hydrogenation of alpha,beta-unsaturated aldehydes and other $\mathrm{C}=\mathrm{O}$ and $\mathrm{C}=\mathrm{C}$ bonds containing compounds. Top. Catal. 1998, 5, 51-62. [CrossRef]

14. Reyes, P.; Rodr, C. Promoting effect of Mo on the selective hydrogenation of cinnamaldehyde on $\mathrm{Rh} / \mathrm{SiO}$ catalysts. Catal. Lett. 2000, 69, 27-32. [CrossRef]

15. Liu, X.; Cheng, S.; Long, J.; Zhang, W.; Liu, X.; Wei, D. MOFs-Derived Co@CN bi-functional catalysts for selective transfer hydrogenation of $\alpha, \beta$-unsaturated aldehydes without use of base additives. Mater. Chem. Front. 2017. [CrossRef]

16. Coq, B.; Kumbhar, P.S.; Moreau, C.; Moreau, P.; Warawdekar, M.G. Liquid-Phase Hydrogenation of Cinnamaldehyde Over Supported Ruthenium Catalysts-Influence of Particle-Size, Bimetallics and Nature of Support. J. Mol. Catal. 1993, 85, 215-228. [CrossRef]

17. Galvagno, S.; Donato, A.; Neri, G.; Pietropaolo, R.; Pietropaolo, D. Hydrogenation of cinnamaldehyde over platinum catalysts: Influence of addition of metal chlorides. J. Mol. Catal. 1989, 49, 223-232. [CrossRef]

18. Galvagno, S.; Poltarzewski, Z.; Donato, A.; Neri, G.; Pietropaolo, R. Selective hydrogenation of $\alpha, \beta$-unsaturated aldehydes to give unsaturated alcohols over platinum-germanium catalysts. J. Chem. Soc. Commun. 1998, 5, 51-62. 
19. Zheng, Q.; Wang, D.; Yuan, F.; Han, Q.; Dong, Y.; Liu, Y.; Niu, X.; Zhu, Y. An Effective Co-promoted Platinum of Co-Pt/SBA-15 Catalyst for Selective Hydrogenation of Cinnamaldehyde to Cinnamyl Alcohol. Catal. Lett. 2016, 146, 1535-1543. [CrossRef]

20. Shi, Y.-S.; Yuan, Z.-F.; Wei, Q.; Sun, K.-Q.; Xu, B.-Q. Pt-FeO ${ }_{x} / \mathrm{SiO}_{2}$ catalysts prepared by galvanic displacement show high selectivity for cinnamyl alcohol production in the chemoselective hydrogenation of cinnamaldehyde. Catal. Sci. Technol. 2016, 6, 7033. [CrossRef]

21. Toebes, M.L.; Zhang, Y.; Hájek, J.; Alexander Nijhuis, T.; Bitter, J.H.; Jos Van Dillen, A.; Murzin, D.Y.; Koningsberger, D.C.; De Jong, K.P. Support effects in the hydrogenation of cinnamaldehyde over carbon nanofiber-supported platinum catalysts: Characterization and catalysis. J. Catal. 2004, 226, 215-225. [CrossRef]

22. He, S.; Xie, L.; Che, M.; Chan, H.C.; Yang, L.; Shi, Z.; Tang, Y.; Gao, Q. Chemoselective hydrogenation of $\alpha, \beta$-unsaturated aldehydes on hydrogenated MoOx nanorods supported iridium nanoparticles. J. Mol. Catal. A Chem. 2016, 425, 248-254. [CrossRef]

23. Han, Q.; Liu, Y.; Wang, D.; Yuan, F.; Niu, X.; Zhu, Y. Effect of carbon nanosheets with different graphitization degrees as a support of noble metals on selective hydrogenation of cinnamaldehyde. RSC Adv. 2016, 6, 98356-98364. [CrossRef]

24. Guo, Z.; Xiao, C.; Maligal-Ganesh, R.V.; Zhou, L.; Goh, T.W.; Li, X.; Tesfagaber, D.; Thiel, A.; Huang, W. $\mathrm{Pt}$ nanoclusters confined within metal-organic framework cavities for chemoselective cinnamaldehyde hydrogenation. ACS Catal. 2014, 4, 1340-1348. [CrossRef]

25. van de Moesdijk, Cornelis G.M.; Bosma, Marcel A.R. Process for the Preparation of $\alpha$ - $\beta$ Unsaturated Alcohols. U.S. Patent 4,745,234, 17 May 1988.

26. Shirai, M.; Tanaka, T.; Arai, M. Selective hydrogenation of $\alpha, \beta$-unsaturated aldehyde to unsaturated alcohol with supported platinum catalysts at high pressures of hydrogen. J. Mol. Catal. A Chem. 2001, 168, 99-103. [CrossRef]

27. Roberge, D.M.; Ducry, L.; Bieler, N.; Cretton, P.; Zimmermann, B. Microreactor Technology: A Revolution for the Fine Chemical and Pharmaceutical Industries? Chem. Eng. Technol. 2005, 28, 318-323. [CrossRef]

28. Wiles, C.; Watts, P. Continuous flow reactors: A perspective. Green Chem. 2012, 14, 38-54. [CrossRef]

29. Hessel, V.; Kralisch, D.; Kockmann, N. Novel Process Windows: Innovative Gates to Intensified and Sustainable Chemical Processes; John Wiley \& Sons: Hoboken, NJ, USA, 2014; ISBN 3527328580.

30. Jähnisch, K.; Hessel, V.; Löwe, H.; Baerns, M. Chemistry in microstructured reactors. Angew. Chem. Int. Ed. 2004, 43, 406-446. [CrossRef] [PubMed]

31. Durndell, L.J.; Wilson, K.; Lee, A.F. Platinum-catalysed cinnamaldehyde hydrogenation in continuous flow. RSC Adv. 2015, 5, 80022-80026. [CrossRef]

32. Cherkasov, N.; Al-rawashdeh, M.; Ibhadon, A.O.; Rebrov, E.V. Scale up study of capillary microreactors in solvent-free semihydrogenation of 2-methyl-3-butyn-2-ol. Catal. Today 2016, 273, 205-212. [CrossRef]

33. Vaccaro, L.; Lanari, D.; Marrocchi, A.; Strappaveccia, G. Flow approaches towards sustainability. Green Chem. 2014, 16, 3680. [CrossRef]

34. Niesz, K.; Hornyak, I.; Borcsek, B.; Darvas, F. Nanoparticle synthesis completed with in situ catalyst preparation performed on a high-pressure high-temperature continuous flow reactor. Microfluid. Nanofluid. 2008, 5, 411-416. [CrossRef]

35. Avril, A.; Hornung, C.H.; Urban, A.; Fraser, D.; Horne, M.; Veder, J.-P.; Tsanaktsidis, J.; Rodopoulos, T.; Henry, C.; Gunasegaram, D.R. Continuous flow hydrogenations using novel catalytic static mixers inside a tubular reactor. React. Chem. Eng. 2017, 2, 180-188. [CrossRef]

36. Borodziński, A.; Bonarowska, M. Relation between Crystallite Size and Dispersion on Supported Metal Catalysts. Langmuir 1997, 13, 5613-5620. [CrossRef]

37. Holbrook, B.P.M.; Rajagopalan, R.; Dronvajjala, K.; Choudhary, Y.K.; Foley, H.C. Molecular sieving carbon catalysts for liquid phase reactions: Study of alkene hydrogenation using platinum embedded nanoporous carbon. J. Mol. Catal. A Chem. 2013, 367, 61-68. [CrossRef]

38. Su, J.; Chen, J.S. Synthetic porous materials applied in hydrogenation reactions. Microporous Mesoporous Mater. 2017, 237, 246-259. [CrossRef]

39. Ma, Y.; Han, L.; Miyasaka, K.; Oleynikov, P.; Che, S.; Terasaki, O. Structural study of hexagonal close-packed silica mesoporous crystal. Chem. Mater. 2013, 25, 2184-2191. [CrossRef]

40. Beaucage, G. Approximations Leading to a Unified Exponential/Power-Law Approach to Small-Angle Scattering. J. Appl. Crystallogr. 1995, 28, 717-728. [CrossRef] 
41. Ilavsky, J.; Jemian, P.R. Irena: Tool suite for modeling and analysis of small-angle scattering. J. Appl. Crystallogr. 2009, 42, 347-353. [CrossRef]

42. Kataoka, T.; Dumesic, J.A. Acidity of unsupported and silica-supported vanadia, molybdena, and titania as studied by pyridine adsorption. J. Catal. 1988, 112, 66-79. [CrossRef]

43. Cardona-Martínez, N.; Dumesic, J.A. Acid strength of silica-alumina and silica studied by microcalorimetric measurements of pyridine adsorption. J. Catal. 1990, 125, 427-444. [CrossRef]

44. Dang, Z.; Anderson, B.G.; Amenomiya, Y.; Morrow, B.A. Silica-supported zirconia. 1. Characterization by infrared spectroscopy, temperature-programmed desorption, and X-ray diffraction. J. Phys. Chem. 1995, 99, 14437-14443. [CrossRef]

45. Wallin, M.; Grönbeck, H.; Spetz, A.L.; Eriksson, M.; Skoglundh, M. Vibrational analysis of $\mathrm{H}_{2}$ and $\mathrm{D}_{2}$ adsorption on $\mathrm{Pt} / \mathrm{SiO}_{2}$. J. Phys. Chem. B 2005, 109, 9581-9588. [CrossRef] [PubMed]

46. Regenhardt, S.A.; Trasarti, A.F.; Meyer, C.I.; Garetto, T.F.; Marchi, A.J. Selective gas-phase conversion of maleic anhydride to propionic acid on Pt-based catalysts. Catal. Commun. 2013, 35, 59-63. [CrossRef]

47. Santiago-Pedro, S.; Tamayo-Galván, V.; Viveros-García, T. Effect of the acid-base properties of the support on the performance of $\mathrm{Pt}$ catalysts in the partial hydrogenation of citral. Catal. Today 2013, 213, 101-108. [CrossRef]

48. Zhang, Y.; Chen, C.; Gong, W.; Song, J.; Su, Y.; Zhang, H.; Wang, G.; Zhao, H. One-pot redox synthesis of $\mathrm{Pt} / \mathrm{Fe}_{3} \mathrm{O}_{4}$ catalyst for efficiently chemoselective hydrogenation of cinnamaldehyde. RSC Adv. 2017, 7, 21107-21113. [CrossRef]

49. Wang, D.; Zhu, Y.; Tian, C.; Wang, L.; Zhou, W.; Dong, Y.; Han, Q.; Liu, Y.; Yuan, F.; Fu, H. Synergistic effect of $\mathrm{Mo}_{2} \mathrm{~N}$ and $\mathrm{Pt}$ for promoted selective hydrogenation of cinnamaldehyde over Pt-Mo $\mathrm{Mo}_{2} \mathrm{~N} / \mathrm{SBA}-15$. Catal. Sci. Technol. 2016, 6, 2403-2412. [CrossRef]

50. Hu, Q.; Wang, S.; Gao, Z.; Li, Y.; Zhang, Q.; Xiang, Q.; Qin, Y. The precise decoration of Pt nanoparticles with Fe oxide by atomic layer deposition for the selective hydrogenation of cinnamaldehyde. Appl. Catal. B Environ. 2017, 218, 591-599. [CrossRef]

51. Zhu, Y.; Zaera, F. Selectivity in the catalytic hydrogenation of cinnamaldehyde promoted by $\mathrm{Pt} / \mathrm{SiO} 2$ as a function of metal nanoparticle size. Catal. Sci. Technol. 2014, 4, 955-962. [CrossRef]

52. Garkhedkar, A.M.; Shingote, S.K.; Rane, V.H.; Kelkar, A.A.; Ranade, V.V. Intensifying Hydrogenation of Cinnamaldehyde to Cinnamyl Alcohol: Catalyst, Solvent and Operating Conditions. Indian Chem. Eng. 2015, 57, 219-239. [CrossRef]

53. Shi, J.; Zhang, M.; Du, W.; Ning, W.; Hou, Z. $\mathrm{SnO}_{2}$-isolated $\mathrm{Pt}_{3} \mathrm{Sn}$ alloy on reduced graphene oxide: An efficient catalyst for selective hydrogenation of $\mathrm{C}=\mathrm{O}$ in unsaturated aldehydest. Catal. Sci. Technol. 2015, 5, 3108-3112. [CrossRef]

54. Koo-Amornpattana, W.; Winterbottom, J.M. Pt and Pt-alloy catalysts and their properties for the liquid-phase hydrogenation of cinnamaldehyde. Catal. Today 2001, 66, 277-287. [CrossRef]

55. Chatterjee, M.; Ikushima, Y.; Zhao, F.Y. Highly efficient hydrogenation of cinnamaldehyde catalyzed by Pt-MCM-48 in supercritical carbon dioxide. Catal. Lett. 2002, 82, 141-144. [CrossRef]

56. Chatterjee, M.; Ikushima, Y.; Zhao, F. Completely selective hydrogenation of trans-cinnamaldehyde to cinnamyl alcohol promoted by a Ru-Pt bimetallic catalyst supported on MCM-48 in supercritical carbon dioxide. New J. Chem. 2002, 27, 510-513. [CrossRef]

57. Shokouhimehr, M. Magnetically Separable and Sustainable Nanostructured Catalysts for Heterogeneous Reduction of Nitroaromatics. Catalysts 2015, 5, 534-560. [CrossRef]

58. Cherkasov, N.; Jadvani, V.; Mann, J.; Losovyj, Y.B.; Shifrina, Z.B.; Bronstein, L.M.; Rebrov, E.V. Hydrogenation of bio-oil into higher alcohols over $\mathrm{Ru} / \mathrm{Fe}_{3} \mathrm{O}_{4}-\mathrm{SiO}_{2}$ catalysts. Fuel Process. Technol. 2017, 167, 738-746. [CrossRef]

59. Mahmoud, S.; Hammoudeh, A.; Gharaibeh, S.; Melsheimer, J. Hydrogenation of cinnamaldehyde over sol-gel $\mathrm{Pd} / \mathrm{SiO}_{2}$ catalysts: Kinetic aspects and modification of catalytic properties by $\mathrm{Sn}, \mathrm{Ir}$ and $\mathrm{Cu}$ additives. J. Mol. Catal. A Chem. 2002, 178, 161-167. [CrossRef]

60. Yue, J. Multiphase flow processing in microreactors combined with heterogeneous catalysis for efficient and sustainable chemical synthesis. Catal. Today 2017, 1-17. [CrossRef]

61. Tanimu, A.; Jaenicke, S.; Alhooshani, K. Heterogeneous catalysis in continuous flow microreactors: A review of methods and applications. Chem. Eng. J. 2017, 327, 792-821. [CrossRef] 
62. Van Herk, D.; Castaño, P.; Makkee, M.; Moulijn, J.A.; Kreutzer, M.T. Catalyst testing in a multiple-parallel, gas-liquid, powder-packed bed microreactor. Appl. Catal. A Gen. 2009, 365, 199-206. [CrossRef]

63. Al-Rawashdeh, M.; Yu, F.; Nijhuis, T.A.; Rebrov, E.V.; Hessel, V.; Schouten, J.C. Numbered-up gas-liquid micro/milli channels reactor with modular flow distributor. Chem. Eng. J. 2012, 207-208, 645-655. [CrossRef]

64. Al-Rawashdeh, M.M.; Yue, F.; Patil, N.G.; Nijhuis, T.A.; Hessel, V.; Schouten, J.C.; Rebrov, E.V. Designing Flow and Temperature Uniformities in Parallel Microchannels Reactor Ma'moun. AIChE J. 2014, 60, 1941-1952. [CrossRef]

65. Cherkasov, N.; Ibhadon, A.O.; Rebrov, E.V. Method of Forming a Coating. WO2017220590, 20 June 2017.

66. Cherkasov, N.; Rebrov, E.V. Updated Catalyst Coating Method for Use in Flow Fine Chemical Synthesis. UK Patent Application No. 17150 86.3, 19 September 2017.

67. Cherkasov, N.; Ibhadon, A.O.; Rebrov, E.V. Novel synthesis of thick wall coatings of titania supported Bi poisoned Pd catalysts and application in selective hydrogenation of acetylene alcohols in capillary microreactors. Lab Chip 2015, 15, 1952-1960. [CrossRef] [PubMed]

68. Cherkasov, N.; Ibhadon, A.O.; McCue, A.; Anderson, J.A.; Johnston, S.K. Palladium-bismuth intermetallic and surface-poisoned catalysts for the semi-hydrogenation of 2-methyl-3-butyn-2-ol. Appl. Catal. A Gen. 2015, 497, 22-30. [CrossRef]

69. Bai, Y.; Li, W.; Liu, C.; Yang, Z.; Feng, X.; Lu, X.; Chan, K.-Y. Stability of Pt nanoparticles and enhanced photocatalytic performance in mesoporous Pt-(anatase $/ \mathrm{TiO}_{2}(\mathrm{~B})$ ) nanoarchitecture. J. Mater. Chem. 2009, 19, 7055. [CrossRef]

70. Schneider, C.A.; Rasband, W.S.; Eliceiri, K.W. NIH Image to ImageJ: 25 years of image analysis. Nat. Methods 2012, 9, 671-675. [CrossRef] [PubMed]

71. Vaittinen, O.; Metsälä, M.; Persijn, S.; Vainio, M.; Halonen, L. Adsorption of ammonia on treated stainless steel and polymer surfaces. Appl. Phys. B 2014, 115, 185-196. [CrossRef]

72. Cherkasov, N.; Bai, Y.; Rebrov, E. Process Intensification of Alkynol Semihydrogenation in a Tube Reactor Coated with a Pd/ZnO Catalyst. Catalysts 2017, 7, 358. [CrossRef]

73. Cherkasov, N.; Ibhadon, A.O.; Rebrov, E.V. Solvent-free Semihydrogenation of Acetylene Alcohols in a Capillary Reactor coated with a Pd-Bi/ $\mathrm{TiO}_{2}$ Catalyst. Appl. Catal. A Gen. 2016, 515, 108-115. [CrossRef]

(C) 2018 by the authors. Licensee MDPI, Basel, Switzerland. This article is an open access article distributed under the terms and conditions of the Creative Commons Attribution (CC BY) license (http:/ / creativecommons.org/licenses/by/4.0/). 